\title{
Comprou, levou? Justaposição: procedimento sintático comum em propagandas
}

\section{Comprou, levou? Juxtaposition: common syntactic procedure in advertisements}

Violeta Virginia Rodrigues ${ }^{1}$, Adriana Cristina Lopes Gonçalves ${ }^{2}$

Doutora em Letras. Professor Associado de Lingua Portuguesa da Universidade Federal do Rio de Janeiro (UFRJ).

violetarodrigues@uol.com.br

Aluna de pós-graduação em Letras Vernáculas - Lingua Portuguesa - da Faculdade

adrianaclgoncalves@hotmail.com
RESUMO: Neste artigo, pretende-se defender a hipótese de que a justaposição pode ser vista como um procedimento sintático, que não se restringe ao âmbito do período composto por coordenação e, ainda, não simplesmente como um subtipo de uma das orações coordenadas - as assindéticas. Para tanto, recorre-se à noção de interdependência semântica e também aos aspectos prosódicos contorno entoacional e pausa, para diferenciar os casos de coordenação dos de justaposição. 0 aporte teórico utilizado envolve autores funcionalistas como Mann \& Thompson (1986), Decat (2001) e ainda trabalhos da área da publicidade, como os de Sandmann (2010), só para citar alguns. Os (65) sessenta e cinco dados analisados são provenientes de portfólios de agências publicitárias vinculadas à Associação Brasileira das Agências de Publicidade (ABAP).

PalaVras-CHAVE: Justaposição; Proposição relacional; Funcionalismo.

ABSTRACT: In this article, we intend to defend the hypothesis that the juxtaposition can be viewed as a syntactic procedure, which is not restricted to the compound period for independent clause and, further, not simply as a subtype of the coordination process - the asyndetic coordination clause. It is based on the notion of semantic interdependence and the prosodic aspects as contour intonation and pauses to differentiate cases of coordination of juxtaposition. The theoretical approach involves functionalist authors such as Mann \& Thompson (1986), Decat (2001) and Sandmann (2010) in the advertising area, to name a few. The (65) sixty-five analyzed pieces of data were collected from portfolios of advertising agencies linked to the Brazilian Association of Advertising Agencies (ABAP).

KEYWORDS: Juxtaposition; Relational proposition; Functionalism. 


\section{Introdução}

$\mathrm{N}$

a tradição gramatical, quando se menciona o conceito de justaposição, este normalmente é associado às orações coordenadas assindéticas, usando-se para exemplificar isso casos em que supostamente haveria tanto autonomia sintática quanto semântica entre as orações articuladas umas às outras.

Em propagandas brasileiras impressas, é comum observar slogans com sintagmas nominais e sintagmas verbais justapostos, ou seja, uns colocados ao lado dos outros. A possibilidade de justapor, apor e adjungir vocábulos e/ou orações é frequente na língua. Sintaticamente, no âmbito do período composto, geralmente essa ideia só aparece na coordenação assindética, mas, ao contrário do que a gramática normativa brasileira nos leva a crer, não há uma autonomia semântica entre os sintagmas e/ou orações, mas sim, uma interdependência semântica e sintática entres esses.

Assim, o presente artigo tem como objetivo defender que a justaposição pode ser vista como um procedimento sintático, que não se restringe ao âmbito do período composto por coordenação e, ainda, não simplesmente como um subtipo de uma das orações coordenadas - as assindéticas.

O corpus deste estudo é constituído por 65 (sessenta e cinco) propagandas compostas por cláusulas justapostas, que foram recolhidas de portfólios de agências publicitárias vinculadas à Associação Brasileira das Agências de Publicidade (ABAP), dos estados do Rio de Janeiro, São Paulo, Bahia e Ceará. Partimos, pois, da hipótese de que, no corpus analisado, a justaposição é um procedimento sintático comum em propagandas impressas, independente da região em que as mesmas foram produzidas.

O aporte teórico utilizado nesta pesquisa é o funcionalista e adotamos deste principalmente as noções de cláusula e de proposição relacional. Esta última noção foi proposta por Mann \& Thompson (1986) e aplicada ao português por Decat (2001); tais autores representam fonte bibliográfica importante para este estudo. Recorremos, além destes, aos trabalhos de Ney (1955), Oiticica (1942), Dias (2009) e Sandmann (2010).

Para alcançar nosso objetivo, este artigo se organiza da seguinte forma: inicialmente fazemos a apresentação do tema e em seguida explicitamos os pressupostos teóricos adotados. Neste momento, abordamos, na perspectiva funcionalista, as noções de cláusula e de proposição relacional; logo depois, analisamos alguns dados do corpus, com base na noção de interdependência semântica, tal como proposta por Ney (1955), associando-a a fatores prosódicos, para comprovar a hipótese de que a justaposição é um procedimento sintático diferente da coordenação.

$\mathrm{Na}$ apresentação do tema, comentamos as abordagens vinculadas à Gramática Tradicional, doravante GT, como se poderá constatar.

\section{Apresentação do tema}

A maioria das gramáticas, que seguem a Nomenclatura Gramatical Brasileira, doravante NGB, contempla somente os processos de coordenação e subordinação para a estruturação do período composto e usa a noção de justaposição associando-a principalmente ao âmbito das orações coordenadas assindéticas, conforme já apontamos no início deste artigo.

O questionamento da suposta independência sintática e semântica na articulação das orações coordenadas, que estendemos para o âmbito dos vocábulos e dos sintagmas, encontra respaldo em Garcia (1975) e Soares (1978), que defendem a existência da "subordinação psicológica" ou semântica nas coordenadas assindéticas, ou seja, aquelas que vêm ligadas umas às outras sem nexo conjuntivo. Portanto, seguindo o raciocínio destes autores, as orações coordenadas podem ter autonomia sintática, mas não necessariamente semântica, porque a ordem ou posição em que as orações 
são usadas no contexto pode determinar uma relação de dependência semântica entre elas. Por isso, a justaposição, quando mencionada, acaba se restringindo à possibilidade de se colocar uma oração ao lado da outra sem se considerar uma possível relação semântica entre os seus núcleos no contexto de uso.

A fim de ratificar os comentários supramencionados, segue a explicação dada por Garcia (1975, p. 20) sobre a "subordinação psicológica", na qual verificamos um conteúdo semântico na articulação das orações umas com as outras, mesmo sem a presença de uma conjunção coordenativa:

(...) muitas vezes, um período só aparentemente é coordenado. Vejamos (...) os três pares de frases seguintes:

a) Não fui à festa do seu aniversário: não me convidaram.

b) Não fui à festa do seu aniversário: passei-lhe um telegrama.

c) Não fui à festa do seu aniversário: não posso saber quem estava lá.

São frases construídas segundo o processo particular da coordenação chamado de justaposição (...): orações não ligadas por conectivo, separadas na fala por uma ligeira pausa com entoação variável, marcada na escrita por vírgula, ponto-e-vírgula ou, mais comumente, dois-pontos.

É outro caso de coordenação ou justaposição gramatical, mas de subordinação psicológica, tanto é certo que o segundo elemento de cada par de frases não goza de autonomia de sentido. A relação entre as duas orações de cada período é de dependência, nitidamente insinuada pelos dois-pontos na escrita, e na fala, por uma entoação da voz que indica:

a) explicação ou causa: Não fui à festa do seu aniversário porque (pois) não me convidaram.

b) oposição (ressalva, atenuação ou compensação): Não fui à festa do seu aniversário, mas (em compensação) passei-lhe um telegrama.

c) conclusão ou conseqüência: Não fui à festa do seu aniversário; portanto (por conseqüência) não posso saber quem estava lá.

Como se observa no excerto de Garcia (1975), embora se recorra à noção de "falsa coordenação" ou "subordinação psicológica" para explicar a relação de dependência semântica entre as orações que gozam de autonomia sintática, a justaposição é considerada um processo "particular de coordenação".
Desse modo, como veremos mais adiante, ao contrário do que é apresentado nas gramáticas tradicionais que seguem a NGB, defende-se aqui que ao invés de uma suposta independência sintática e semântica entre as orações como ocorre na coordenação, há, na justaposição, uma interdependência entre as orações, mesmo sem o uso de conector explícito, interdependência essa que nos leva a depreender um conteúdo semântico na articulação dessas orações no contexto de uso, como se vê em um exemplo retirado do corpus deste estudo:

"Não é o dia, é o lugar." (propaganda da agência de viagens Shangri-lá)

Ao se analisar a Figura 1 a seguir, percebe-se que há uma relação semântica de causa e/ou oposição implícita entre as partes que constituem o período usado no círculo à direita da propaganda, já que ao se observarem as duas imagens que compõem a propaganda, supõe-se que independente do dia da semana, o lugar em que se está é o que determina o estado de satisfação do indivíduo, ou ainda que não é o dia da semana que determina o estado de satisfação do indivíduo, mas sim, o lugar onde este se encontra. A relação de causa pode ser elucidada pela paráfrase: "Já que não é o dia, é o lugar" e a de oposição pela paráfrase: "Não é o dia, mas é o lugar".

Figura 1 - Agência 3 - propaganda Shangri-lá

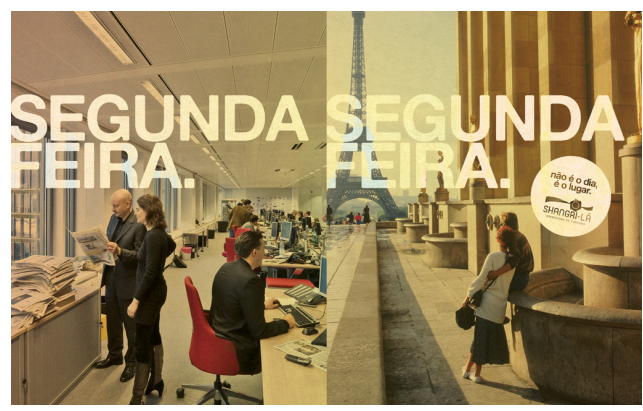

Fonte: http://agencia3.com.br/ (acesso em mar. 2013) 
Como antes mencionamos a noção da independência versus dependência na caracterização principalmente das coordenadas, apontamos rapidamente agora as características apresentadas para os procedimentos sintáticos subordinação e coordenação na GT.

No processo de subordinação, a oração subordinada é caracterizada, de acordo com Bechara (2000, p. 462), como "uma oração dependente do ponto de vista sintático, que sozinha, considerada como unidade material, constitui um texto, se este nela se resumir". Na coordenação, ainda segundo Bechara (2000, p. 476), as coordenadas são caracterizadas como "orações sintaticamente independentes entre si e que se podem combinar para formar grupos oracionais ou períodos compostos". Já a justaposição, quando mencionada, é apresentada meramente como um artifício formal para estruturação das orações ou como sinônimo de orações coordenadas assindéticas, isto é, orações introduzidas sem a presença de conectivo, e sintática e semanticamente independentes. Logo, não há menção à possibilidade de haver subordinação semântica na coordenação.

O Quadro 1 a seguir mostra as definições usadas por cinco gramáticos de linha tradicional para coordenação e subordinação, em que se pode evidenciar a ausência de explicitação da justaposição conforme antes mencionado e a oposição coordenação/subordinação pelo critério da (in)dependência.

As definições reproduzidas no Quadro 1 representam a visão dos gramáticos seguidores da NGB. Dois gramáticos anteriores à NGB, Oiticica (1942) e Ney (1955), consideram a justaposição um processo de composição do período assim como a subordinação e a coordenação. Oiticica (1942) foi o primeiro autor a defender que a justaposição é um processo de composição do período e a classificar as orações justapostas em intercaladas, apostas e adverbiais. Ney (1955, p. 62) afirma que na justaposição há "declaratividade" total, sem uso de conectivo, e que mesmo não havendo conectivo introduzindo as
Quadro 1 - Coordenação \& subordinação no âmbito da GT

\begin{tabular}{|c|c|c|}
\hline Gramático & Coordenação & Subordinação \\
\hline $\begin{array}{l}\text { BECHARA } \\
(2000, \text { p. } 218-219)\end{array}$ & $\begin{array}{l}\text { "Chama-se coordenação à seqüência } \\
\text { de orações em que uma não exerce } \\
\text { função sintática na outra." } \\
\text { Ex.: "Ouve e obedece aos teus } \\
\text { superiores." }\end{array}$ & $\begin{array}{l}\text { "Chama-se subordinação à } \\
\text { seqüência de orações em que uma é } \\
\text { um termo sintático de outra." } \\
\text { Ex.: "Não sei se todos disseram que } \\
\text { não queriam o brinquedo." }\end{array}$ \\
\hline $\begin{array}{l}\text { CUNHA \& CINTRA } \\
(1985, \text { p. 578-579) }\end{array}$ & $\begin{array}{l}\text { "As horas passam, os homens caem, a } \\
\text { poesia fica. } \\
\text { Vemos que as três orações são } \\
\text { da mesma natureza, pois: a) são } \\
\text { autônomas, INDEPENDENTES, isto é, } \\
\text { cada uma tem sentido próprio; } \\
\text { b) não funcionam como TERMOS de } \\
\text { outra oração, nem a eles se referem: } \\
\text { apenas, uma pode enriquecer com o } \\
\text { seu sentido a totalidade da outra. A } \\
\text { tais orações autônomas dá-se o nome } \\
\text { de COORDENADAS, e o período por } \\
\text { elas formado diz-se COMPOSTO POR } \\
\text { COORDENAÇÃO." }\end{array}$ & $\begin{array}{l}\text { "As orações sem autonomia } \\
\text { gramatical, isto é, as orações que } \\
\text { funcionam como termos essenciais, } \\
\text { integrantes ou acessórios de outra } \\
\text { oração chamam-se SUBORDINADAS. } \\
\text { O período constituído de } \\
\text { orações SUBORDINADAS e uma } \\
\text { oração PRINCIPAL denomina-se } \\
\text { COMPOSTO POR SUBORDINAÇÃO." } \\
\text { Ex.: “O meu André não lhe disse que } \\
\text { temos aí um holandês que trouxe } \\
\text { material novo?” }\end{array}$ \\
\hline $\begin{array}{l}\text { KURY } \\
(2002, \text { p. 62-63) }\end{array}$ & $\begin{array}{l}\text { "Se todas as orações de um período } \\
\text { são independentes, isto é, têm sentido } \\
\text { por si mesmas, e poderiam, por isso, } \\
\text { constituir cada uma um período, } \\
\text { o período se diz COMPOSTO POR } \\
\text { COORDENAÇÃO. } \\
\text { Ex.: "Aqui estou, aqui vivo, aqui } \\
\text { morrerei." (M. de Assis, MA, 4)" }\end{array}$ & $\begin{array}{l}\text { “O período se diz COMPOSTO POR } \\
\text { SUBORDINACCÃO quando haja nele } \\
\text { uma oração PRINCIPAL e uma } \\
\text { ou mais SUBORDINADAS, isto é, } \\
\text { dependentes dela. Pode também } \\
\text { haver orações subordinadas não a } \\
\text { uma principal, mas a um vocativo. } \\
\text { Ex.: "Não permita Deus [que eu } \\
\text { morra.]" }\end{array}$ \\
\hline $\begin{array}{l}\text { LUFT } \\
\text { (1978, p.144-145) }\end{array}$ & $\begin{array}{l}\text { "Período composto por coordenação: } \\
\text { só tem orações independentes } \\
\text { (coordenadas)." } \\
\text { Ex.: "As saudades me convidam, } \\
\text { suspiros me põem a mesa." }\end{array}$ & $\begin{array}{l}\text { "Período composto por } \\
\text { subordinação: tem oração principal } \\
\text { e subordinada(s)." } \\
\text { Ex.: "Quando um não quer, dois não } \\
\text { brigam." }\end{array}$ \\
\hline $\begin{array}{l}\text { ROCHA LIMA } \\
\text { (1998, p. 260-261) }\end{array}$ & $\begin{array}{l}\text { "A comunicação de um pensamento } \\
\text { em sua integridade, pela sucessão } \\
\text { de orações gramaticalmente } \\
\text { independentes - eis o que constitui o } \\
\text { período composto por coordenação." } \\
\text { Ex.: "As senhoras casadas eram bonitas; } \\
\text { porém Sofia primava entre todas." }\end{array}$ & $\begin{array}{l}\text { "No período composto por } \\
\text { subordinação, há uma oração } \\
\text { principal, que traz presa a si, como } \\
\text { dependente, outra ou outras. } \\
\text { Dependentes, porque cada uma tem } \\
\text { seu papel como um dos termos da } \\
\text { oração principal." } \\
\text { Ex.: "É certo que o trem já partiu." }\end{array}$ \\
\hline
\end{tabular}


orações justapostas, há uma dependência de sentido entre elas ${ }^{11}$. Nas palavras do autor:

Na justaposição há declaratividade total, sem conectivo; mas as orações não são interdependentes no sentido. Ex.: "O viúvo teve uma única preocupação: deixar a música."; "não se pode dizer, atalhou o vigário, que isso seja obra do satanás". "O mestre concluíra a obra, há dez meses". No primeiro período, deixar a música é aposto de única preocupação; dizemos pois que é uma oração justaposta aposta. No segundo período, atalhou o vigário é uma justaposta intercalda de citação. No terceiro período, há dez meses é justaposta adverbial. (NEY, 1955, p. 62)

Ao lado, Quadro 2, apresentamos a classificação das orações proposta por Ney (1955) em seu Guia de análise sintática, destacando em negrito sua tipologia para as orações justapostas.

Com base no Quadro 2, ao contrário do que se viu no Quadro 1, representativo dos gramáticos posteriores à NGB, e em consonância com os autores anteriores à NGB, tal como Ney (1955), encontramos neste autor os primeiros subsídios para defender a justaposição como procedimento sintático juntamente com a coordenação e a subordinação.

Como, para trabalhar a língua em uso, uma das principais premissas do Funcionalismo, apenas a visão tradicional não se mostrou suficiente para abarcar todos os dados a serem analisados, foi preciso recorrer a outras noções funcionalistas, que apresentaremos a seguir nos pressupostos teóricos.

\footnotetext{
${ }^{11}$ É importante mencionar que, normalmente, quando se fala de conteúdo semântico nas coordenadas, pensa-se imediatamente nas sindéticas - aquelas que são introduzidas por conjunções coordenativas, não há conjunção, mas, mesmo assim, pode-se estabelecer um conteúdo semântico entre as oraç̃ Portanto, conform
} orações, mas a relação que elas estabelecem umas com as outras no contexto.
Quadro 2 - Classificação das orações, segundo Ney (1955)

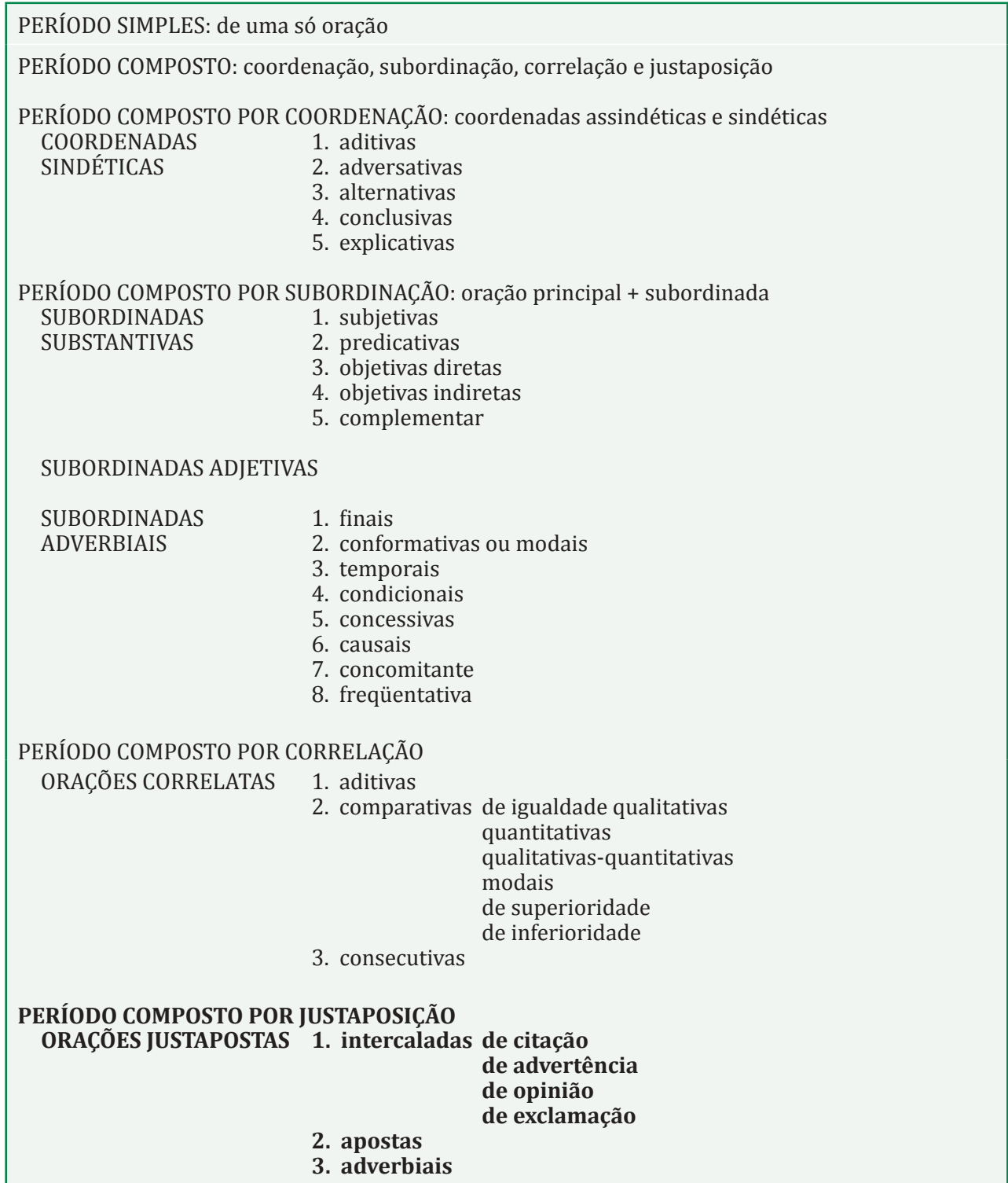




\section{Pressupostos Teóricos}

Para analisarmos os dados de vocábulos e de sintagmas justapostos nas propagandas do corpus, faz-se necessário apresentar brevemente, de acordo com a teoria funcionalista, a noção de cláusula e de proposição relacional. Além disso, faremos também uma análise prosódica de dados justapostos e coordenados, a fim de diferenciar os dois procedimentos anteriormente descritos.

Com base nas leituras de Ford (1992) e Fox (1984), foi possível estabelecer a hipótese de que dois fatores prosódicos - a pausa e a entoação - poderiam diferenciar as propagandas justapostas das coordenadas. Assim, nas cláusulas justapostas, caracterizadas, como vimos antes, por serem interdependentes semanticamente, a pausa não seria um aspecto relevante e a entoação entre os elementos justapostos seria ascendente. Já nas cláusulas coordenadas, por estas serem independentes sintática e semanticamente, conforme nos leva a pensar a análise tradicional, normalmente haveria pausa entre os elementos coordenados e a entoação seria descendente.

\subsection{Funcionalismo}

Conforme já dissemos, este estudo adota a perspectiva funcionalista, principalmente, em um de seus princípios mais basilares, ou seja, o de trabalhar a língua em uso e aqui ela é analisada no gênero propaganda publicitária. Por meio das propagandas se contemplam as funções discursivas em âmbito textual e interacional.

\subsection{A noção de cláusula}

Para a análise do corpus, isto é, das propagandas recolhidas de contextos reais de interação comunicativa, o conceito de oração não se mostrou totalmente eficiente aos nossos propósitos, visto que foram encontrados casos de justaposição que não eram orações, mas que configuravam unidades comunicativas nos contextos de uso, o que nos levou a adotar a noção de cláusula como unidade de análise.

Considera-se cláusula neste estudo a unidade de informação que pode ou não conter núcleo verbal. Sendo assim, ao adotar a noção de cláusula, não se leva apenas em consideração a forma, mas sim, a capacidade discursiva de combinação de uma parte com a outra formando uma unidade informativa, podendo esta se constituir apenas de um vocábulo, de um sintagma e, até mesmo, de uma oração ou período.

Esta acepção foi adotada a partir da leitura do trabalho de Dias (2009). Em sua pesquisa, a autora atesta a justaposição em provérbios como "casa de ferreiro, espeto de pau". Segundo ela (cf. Dias: 2009, p. 12), apesar de os provérbios, em sua maioria, serem constituídos por sintagmas nominais, e, portanto, não constituírem nem orações e nem períodos compostos, há uma articulação hipotática, uma relação circunstancial que emerge entre as unidades, que constituem tais provérbios, configurando assim, para a autora, uma interdependência funcional-discursiva entre suas partes, tornando possível, portanto, relações adverbiais implícitas ou leituras hipotáticas, tais como "Embora a casa seja de ferreiro, o espeto é de pau", referindo-se ao provérbio supracitado.

O trabalho de Dias (2009) permitiu comprovar a hipótese de que nas propagandas que constituem o presente corpus pode haver sintagmas nominais, sintagmas verbais, períodos simples e compostos justapostos.

\subsection{Proposição relacional}

Para uma melhor análise das possíveis leituras hipotáticas que não são necessariamente explicitadas através de conectivos e que podem relacionar duas cláusulas ou duas sequências maiores de texto, adotamos a noção de proposição relacional de Mann \& Thompson (1986). 
Segundo Decat (2001), que adotou a proposta destes autores para o português, proposição relacional diz respeito às leituras que emergem dentro do (con)texto através da combinação de cláusulas introduzidas ou não por um conector. Portanto, não é apenas o conector que sozinho determina o conteúdo da cláusula, mas a articulação/relação entre as cláusulas com a sua utilização ou não num contexto de uso que fará com que os usuários da língua identifiquem as proposições relacionais ali possíveis. Essa ideia nos auxiliou na observação das leituras que poderiam emergir das propagandas analisadas, como, por exemplo:

"Achou bonito? Espera chegar lá embaixo." (slogan da propaganda da Eletrobras sobre a conscientização dos prejuízos de soltar balão)

É possível, nesta propaganda, inferir uma leitura de condição, mesmo sem a presença do conector condicional prototípico se, como atestam vários estudos (cf. Said Ali: 1969, Ferreira: 2007, só para citar alguns): "Se achou bonito, espera chegar lá embaixo". Ou, ainda, uma leitura concessiva: "Embora tenha achado bonito, espera chegar lá embaixo". Tal fato se justifica porque as nuances de condição e concessão envolvem sequências textuais mais argumentativas nas quais se parte de uma tese, hipótese que deverá/poderá ser comprovada ou não por meio de argumentos contrários ou favoráveis ao que o autor do texto defende.

Corroborando Said Ali (1969), Ferreira (2007) verificou que as cláusulas condicionais examinadas nos seus corpora apareceram mais frequentemente em textos de caráter argumentativo. Nesses textos, as condicionais, por exemplo, contribuem para a adesão do interlocutor à determinada tese, já que o seu uso contribui para a organização de um discurso que objetiva interferir na opinião do interlocutor.

0 recurso da paráfrase anteriormente utilizado corrobora a afirmação de Decat (2001) de que construções justapostas hipotáticas como "Pagou, passou" ou "Comprou, levou" são estratégias comuns em propagandas, porque atingem com facilidade o objetivo comunicativo deste gênero textual predominantemente persuasivo. A premissa da autora é ratificada pelo trabalho de Sandmann (2010, p. 68) que destaca que "um dos aspectos que possivelmente distingue os textos de propagandas é o que chamamos de simplicidade estrutural". O autor menciona também que o "período composto sem conectivo" é um artifício comum nestes contextos.

Após apresentarmos brevemente a fundamentação teórica deste estudo, passamos agora à aplicação dos pressupostos aos dados do corpus analisado.

\section{Análise dos dados}

\subsection{0 corpus analisado}

O corpus deste estudo é constituído por 65 (sessenta e cinco) propagandas compostas por cláusulas justapostas, encontradas nos portfólios de 23 (vinte e três) agências publicitárias. Esses dados foram coletados de sites de agências de publicidade vinculados à Associação Brasileira das Agências de Publicidade (ABAP), que é um portal constituído de propagandas provenientes de mídia impressa. Foram recolhidos dados de agências do Rio de Janeiro, São Paulo, Bahia e Ceará. Com isso, obtivemos os seguintes números apresentados no Quadro 3:

Quadro 3 - Número de agências e propagandas por cada região da ABAP analisada

\begin{tabular}{|l|c|c|}
\hline $\begin{array}{c}\text { Regiões da ABAP } \\
\text { analisadas }\end{array}$ & $\begin{array}{c}\text { № de agências } \\
\text { credenciadas }\end{array}$ & $\begin{array}{c}\text { № de agências com } \\
\text { propagandas justapostas }\end{array}$ \\
\hline ABAP Rio de Janeiro & 20 agências & 8 agências \\
ABAP São Paulo & 64 agências & 6 agências \\
ABAP Bahia & 20 agências & 5 agências \\
ABAP Ceará & 12 agências & 4 agências \\
\hline
\end{tabular}


Com base nos números apresentados no Quadro 3, vê-se que a justaposição é um procedimento sintático utilizado em propagadas impressas e de diferentes regiões.

Das 65 (sessenta e cinco) propagandas, foi verificado que 48 (quarenta e oito) delas são constituídas por apenas um sintagma verbal, 4 propagandas são constituídas por um ou mais sintagmas nominais e 13 propagandas são constituídas por mais de um sintagma verbal, portanto, um período composto, conforme apresentado no Quadro 4.

Quadro 4 - Estruturas das propagandas

\begin{tabular}{|l|c|}
\hline \multicolumn{1}{|c|}{ Estruturas das propagadas } & Quantidade de propagandas \\
\hline Apenas um sintagma verbal & 48 \\
Um ou mais sintagmas nominais & 4 \\
Mais de um sintagma verbal & 13 \\
\hline
\end{tabular}

As propagandas apresentadas a seguir exemplificam cada estrutura de propaganda apresentada no Quadro 4. Na primeira propaganda, há diversas perguntas compostas apenas por sintagmas verbais, com exceção da resposta, que além deste sintagma tem ainda um sintagma nominal: "Quer saber? Quer se informar? Quer entender? Quer debater? Quer ouvir? Quer ser ouvido? Quer ver? Quer cobrar? Quer se atualizar? Quer se divertir? Quer torcer? Quer ganhar? Quer participar? Quer interagir? Vê o Extra". Neste caso é possível realizar paráfrases como: [Porque/Se] Quer saber? Quer se informar? Quer entender? Quer debater? Quer ouvir? Quer ser ouvido? Quer ver? Quer cobrar? Quer se atualizar? Quer se divertir? Quer torcer? Quer ganhar? Quer participar? Quer interagir? Vê o Extra". Já na segunda propaganda, o slogan é composto por dois sintagmas nominais: "Ligação anônima, sigilo absoluto", sendo possível a realização da paráfrase: [Porque/Se] Ligação anônima, sigilo absoluto. Vale ressaltar que a inferência causal ou condicional na segunda propaganda contribui para a eficiência e credibilidade do Disque Denúncia. Na terceira propaganda, o slogan é composto por mais de um sintagma verbal: "Me aperta, me cheira, me chama de Mon Bijou", constituindo o que tradicionalmente se denomina de período composto por coordenação. Neste caso, é possível mais uma vez realizar a paráfrase [Porque/Quando /Se ] Me aperta, me cheira, me chama de Mon Bijou.

(i) Figura 2 - Agência Simplicidade Criativa - Jornal Extra

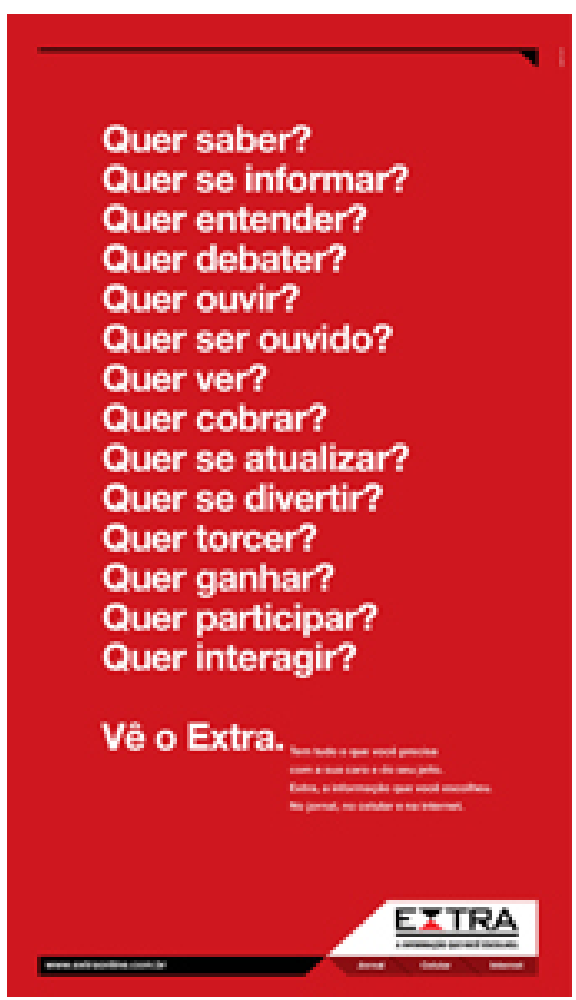

Fonte: <http://www.onzevinteum.com.br/> (acesso em mar. 2013). 
(ii) Figura 3 - Agência 3 - Disque denúncia

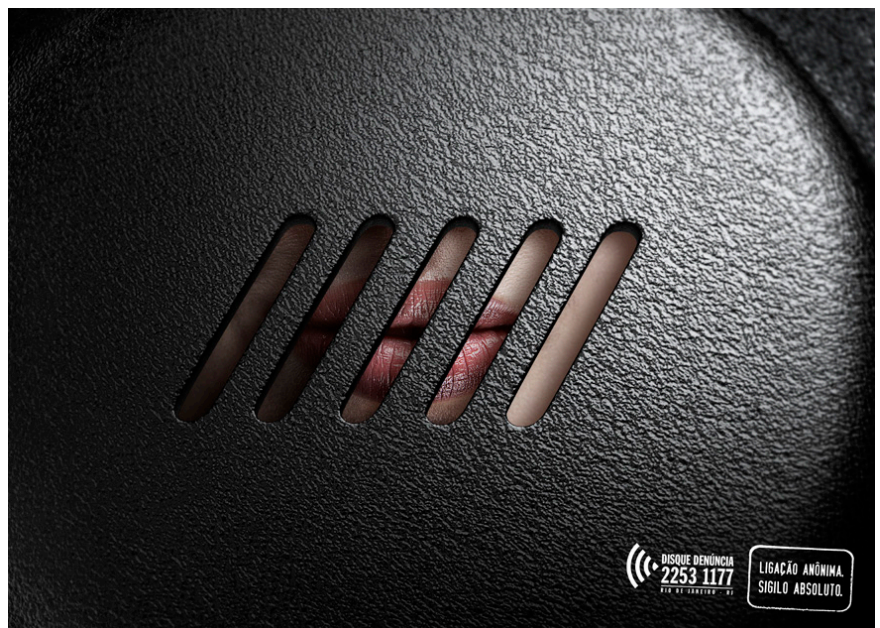

Fonte: <http://agencia3.com.br/> (acesso em mar. 2013).

(iii) Figura 4 - Agência DPZ - Mon Bijou

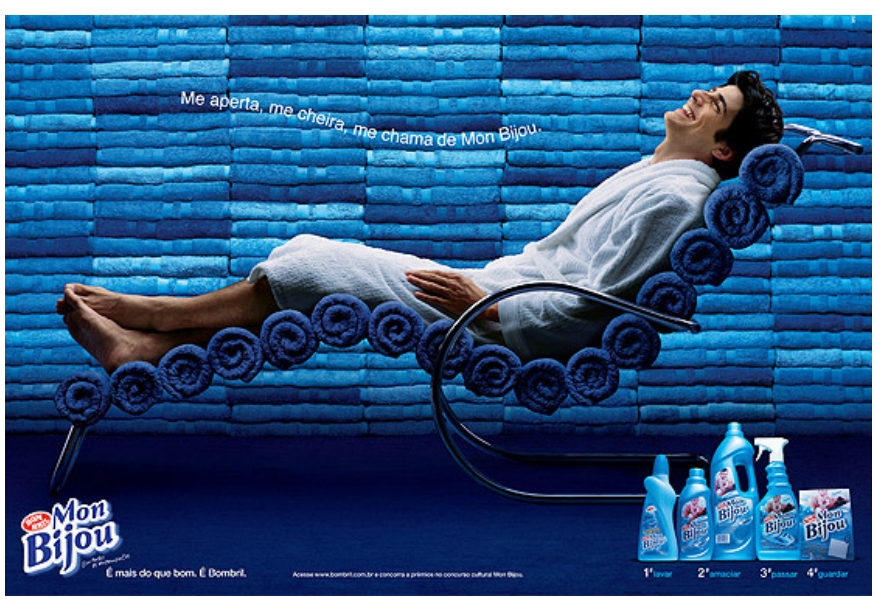

Fonte: <http://www.dpzt.com.br/> (acesso em mar. 2013)

\subsection{Dados analisados}

A partir da análise das 65 (sessenta e cinco) propagandas recolhidas, verificou-se que diversas relações proposicionais podiam emergir na mesma propaganda simultaneamente. A princípio, listamos uma a uma, depois as dividimos em três grupos: o primeiro é o grupo da causalidade (grupo no qual se encontram relações vinculadas à causa, consequência, explicação, conclusão e finalidade), o segundo é o grupo da condicionalidade (neste foram alocadas as relações vinculadas à condição, tempo e proporção) e o terceiro é o grupo da concessividade (neste foram inseridas as relações vinculadas à concessão, adversidade e alternância). Vale mencionar que esses três grupos foram elaborados a partir da leitura dos trabalhos de Azeredo (1990), Halliday (1994) e Mann e Thompson (1986).

Azeredo (1990) divide os conteúdos expressos pelas orações adverbiais em cinco grupos nomeados e distribuídos da seguinte forma: grupo A - situação ou movimento (abrange as orações temporais, proporcionais e locativas), grupo B - causa (abrange as orações causais e condicionais), grupo C - modo (abrange as orações modais, comparativas e conformativas), grupo D - contraste (abrange as orações concessivas e adversativas) e o grupo E - resultado (abrange as orações conclusivas, consecutivas e finais).

Já Halliday (1994), ao defender que os procedimentos sintáticos se dividem no eixo paratático e hipotático, relaciona as orações adverbiais da tradição à hipotaxe de realce (entende-se que hipotaxe de realce, segundo o autor, é o fenômeno de articulação de cláusulas que se combinam, a fim de modificar ou expandir de alguma forma a informação contida em outra cláusula ou porção textual). Assim, o autor divide os principais marcadores de extensão de cláusulas em adição, variação, alternância, tempo, espaço, modo, causa e condição.

Mann e Thompson (1986) apresentam a teoria da Rethorical Structure Theory (RST), uma teoria descritiva que busca estudar a organização do 
texto, caracterizando as relações que se estabelecem entre as partes do mesmo. Essa corrente teórica reconhece proposições explícitas através de conectivos e preposições, bem como as proposições relacionais implícitas que surgem do (con)texto. Os autores ressaltam que não há um número específico de proposições relacionais; estas, ao contrário são identificadas no texto e contribuem para a coerência textual. Algumas delas são: circunstância, elaboração, fundo, solução, motivação, permissão, evidência, justificativa, entre outras. Só a título de exemplo, no âmbito da coordenação, podemos ter a seguinte estrutura "João não esperou, ele foi embora", em que há duas orações apostas; por elaboração a estrutura antes ilustrada em seu contexto de uso pode apresentar a seguinte leitura: "João foi embora, o que surpreendeu a todos".

Assim, com base nos autores e nas correntes teóricas por eles defendidas, elaboramos nossos três grupos de relações proposicionais, conforme mencionado e descrito anteriormente. Ao dividir as propagandas e suas relações proposicionais pelos grupos, obtivemos os seguintes resultados: 0 grupo com maior ocorrência foi o da condicionalidade (em 59 propagandas emergiam as proposições deste grupo), seguido do grupo da causalidade (em 50 propagandas) e, por último, o grupo da concessividade (em 4 propagandas), conforme ilustrado no Quadro 5 a seguir.

Quadro 5 - Relações proposicionais

\begin{tabular}{|l|c|}
\hline \multicolumn{1}{|c|}{ Relações Proposicionais } & \multicolumn{1}{|c|}{$\begin{array}{c}\text { Quantidade de propagandas (com } \\
\text { possibilidade de todas as relações) }\end{array}$} \\
\hline $\begin{array}{l}\text { Causalidade (causa, consequência, explicação, } \\
\text { conclusão e finalidade) }\end{array}$ & 50 \\
$\begin{array}{l}\text { Condicionalidade (condição, tempo e } \\
\text { proporção) }\end{array}$ & 59 \\
$\begin{array}{l}\text { Concessividade (concessão, adversidade e } \\
\text { alternância) }\end{array}$ & 4 \\
\hline
\end{tabular}

A seguir estão dispostas algumas propagandas com suas respectivas paráfrases evidenciando as relações proposicionais por nós identificadas.

(i)

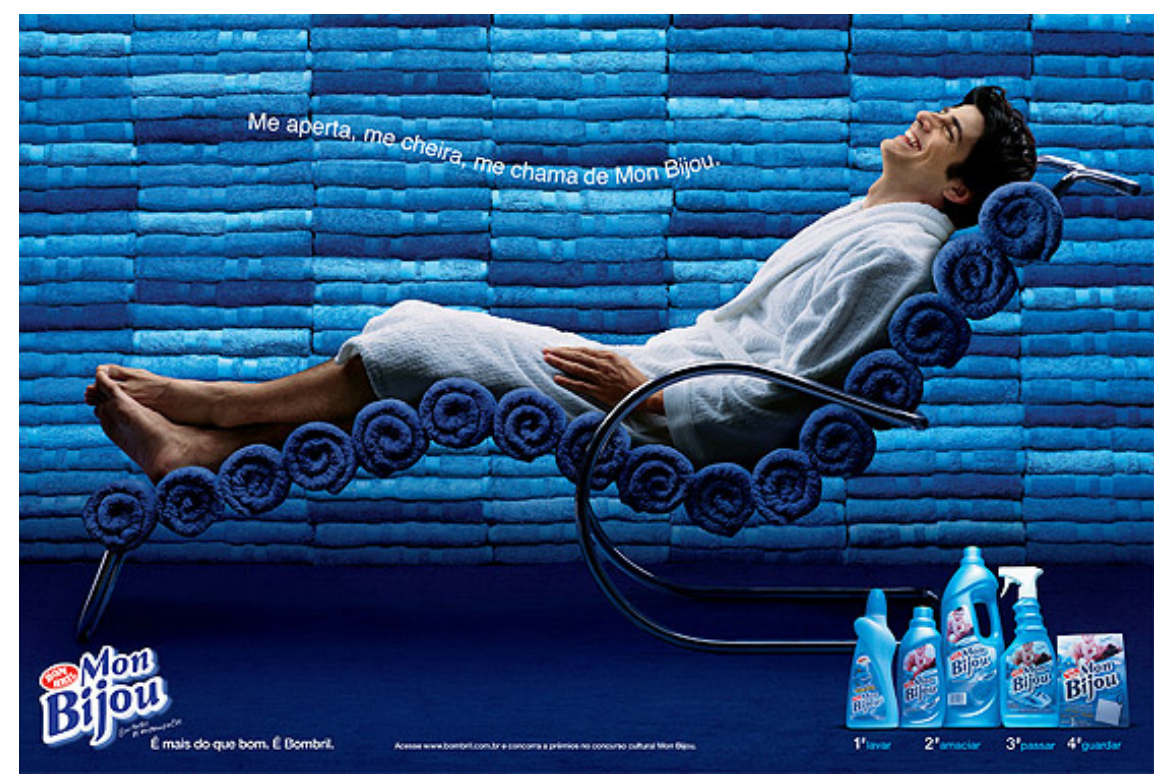

Fonte: <http://www.dpzt.com.br/> (acesso em mar. 2013)

"Me aperta, me cheira, me chama de Mon Bijou."

[Porque / visto que] Me aperta, me cheira, me chama de Mon Bijou. [À medida que /se / quando] Me aperta, me cheira, me chama de Mon Bijou... 
(ii) Figura 5 - Agência Binder - Cultura Inglesa

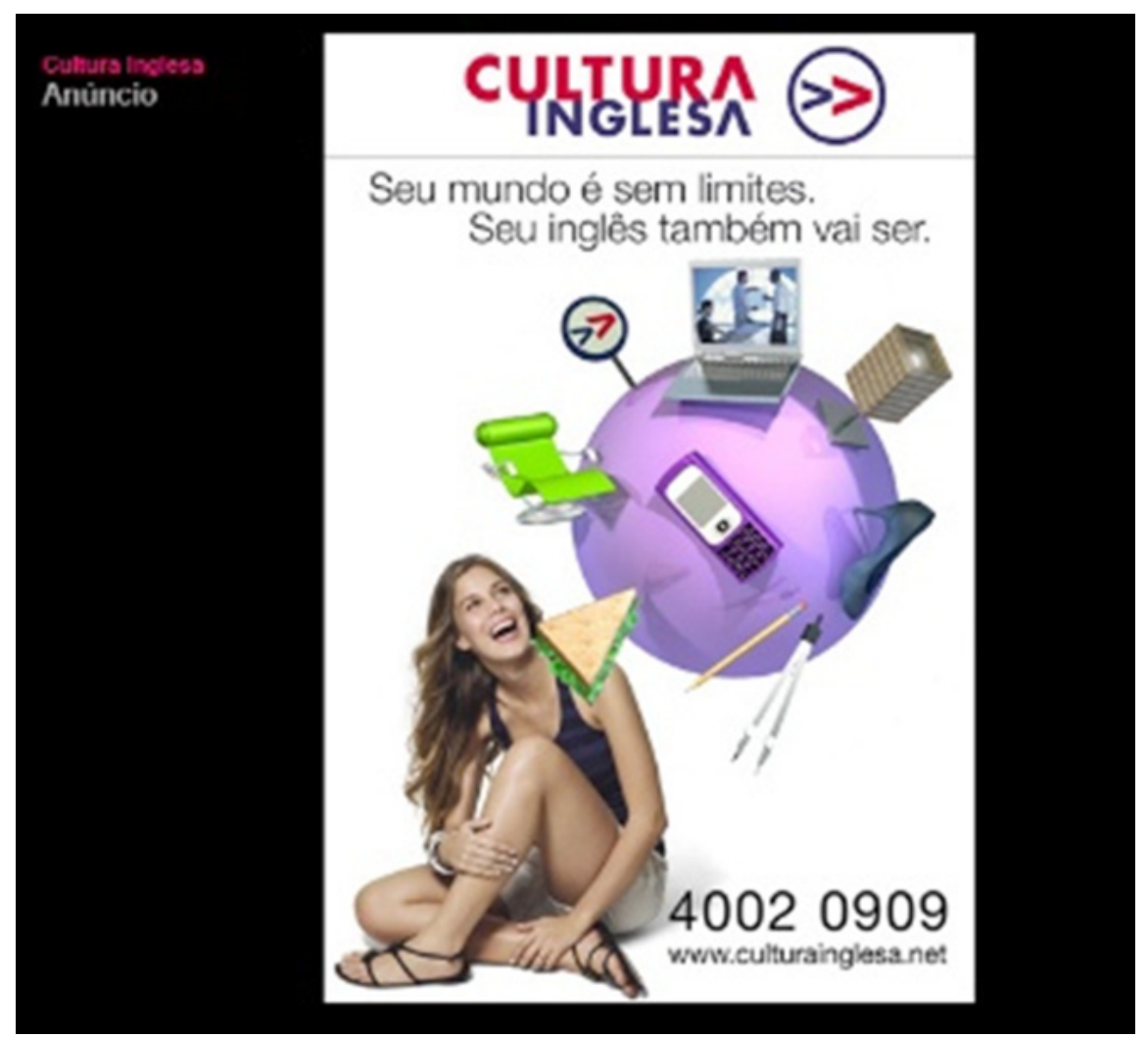

Fonte: <http://www.binder.com.br/binderwp/> (acesso em mar. 2013)

"Seu mundo é sem limites. Seu inglês também vai ser"

(Propaganda Cultura Inglesa)

[Se / à medida que] seu mundo é sem limites. Seu inglês também vai ser.

[Já que/ porque] seu mundo é sem limites. Seu inglês também vai ser.
Como se pode observar pelo Quadro 5, o número de relações proposicionais ultrapassa o número total de propagandas analisadas - 65 (sessenta e cinco) - isto porque, como vimos nas paráfrases em (i) e (ii), de uma mesma propaganda pode emergir mais de uma relação proposicional. As relações proposicionais ligam-se diretamente às possíveis leituras que as estruturas permitem dentro do contexto. Assim, dependendo do contexto, às vezes, optamos por uma determinada interpretação, outras vezes, mesmo com apoio do contexto, a ambiguidade permanece.

Com base na análise de dados apresentada, a partir do número de propagandas encontradas, das diversas estruturas que compõem os slogans das propagandas e das muitas relações proposicionais que podem emergir dessas, verificamos que há uma interdependência semântica entre as cláusulas das propagandas, segundo atestam os trabalhos consultados para a feitura deste estudo.

\subsection{Análise prosódica}

Tendo em vista que só a interdependência semântica não é fator suficiente para caracterizar a justaposição como processo sintático, buscouse, neste estudo, apoio na análise dos fatores prosódicos pausa e entoação para comprovar a hipótese principal deste trabalho, ou seja, que justaposição e coordenação são dois procedimentos sintáticos distintos.

Para tal distinção, foram selecionadas 6 (seis) propagandas do corpus anteriormente apresentado e se buscaram mais 6 (seis) propagandas coordenadas nas agências credenciadas à ABAP Rio de Janeiro. Em seguida, foi pedido a duas informantes que lessem os slogans das propagandas, sendo essas leituras gravadas em um laboratório de acústica e submetidas ao programa Praat, por meio do qual foram aferidos os valores da frequência fundamental (F0) das partes que compõem as cláusulas justapostas e coordenadas analisadas. 
Para ilustrar a análise prosódica empreendida, observem-se os exemplos a seguir.

(i)

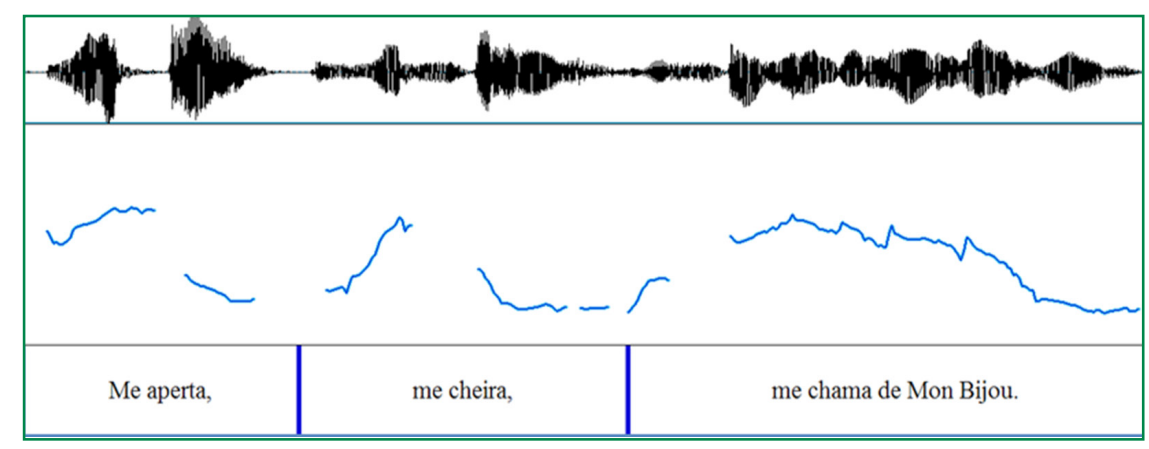

(ii)

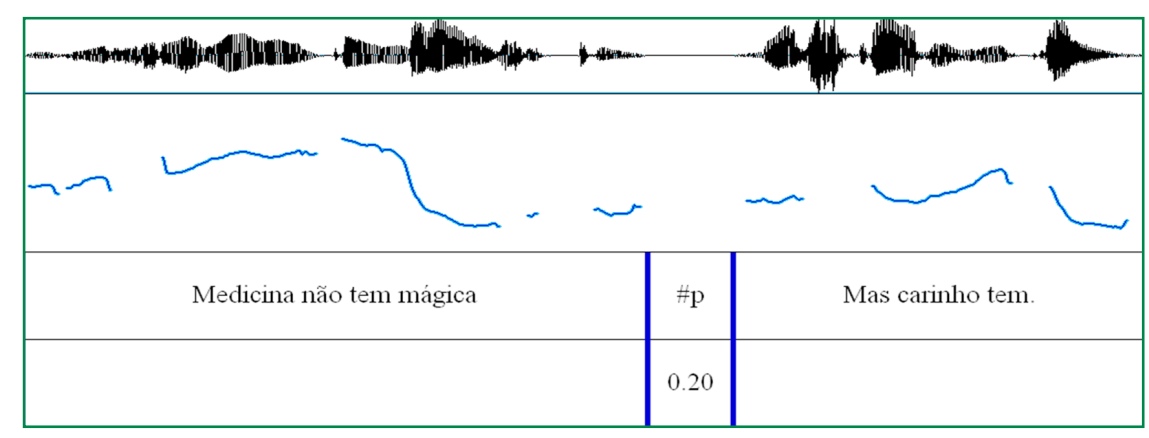

Apesar de ser um teste inicial, as gravações confirmaram o que esperávamos: na imagem (i), pode-se notar que as cláusulas justapostas possuem um tom descendente e que não há pausa entre as cláusulas. Já na imagem (ii), pode-se notar que a entoação é praticamente contínua e que há uma pausa significativa entre as cláusulas. Esta diferenciação quanto à entoação e à pausa demonstra que a justaposição e a coordenação são procedimentos diferentes também na prosódia.

\section{Considerações finais}

Ao fim deste estudo, acreditamos estar no caminho certo para provar a hipótese de que a justaposição é um processo sintático comum em propagandas constituídas por diferentes tipos de cláusula (sintagmas nominais, sintagmas verbais e períodos simples) e que, além disso, podem estabelecer proposições relacionais diversas.

A investigação dos aspectos prosódicos, apesar de ter cumprido com os objetivos propostos, ainda não está de todo concluída. Assim, a análise preliminarmente realizada nos leva a crer que as propagandas justapostas se caracterizam por uma interdependência semântica, por não serem introduzidas por conectivo, não possuírem pausa significativa entre as cláusulas e possuírem uma entoação ascendente por serem mais dependentes semanticamente umas das outras. Já as propagandas coordenadas se caracterizam por uma independência sintática e semântica, por poderem ou não ser introduzidas por conectivo, possuírem pausa significativa entre as cláusulas e por serem menos dependentes semanticamente, apresentando, portanto, uma entoação descendente.

\section{Referências}

AZEREDO, José Carlos de. Iniciação à Sintaxe do Português. Rio de Janeiro: Jorge Zahar Editor, 1990.

BECHARA, Evanildo. Moderna gramática portuguesa. Rio de Janeiro: Lucerna, 2000.

CUNHA, Celso; CINTRA, Lindley. Nova gramática do português contemporâneo. Rio de Janeiro: Lexikon Editora Digital, 2007. 
CHAFE, Wallace L. The Pear Stories: cognitive, cultural, and linguistic aspects of narrative production. Norwood: Ablex, 1980.

DECAT, Maria Beatriz N. Estruturas desgarradas em Língua Portuguesa. Campinas: Pontes, 2001.

DECAT, Maria Beatriz N. Aspectos da gramática do português: uma abordagem funcionalista. Campinas, SP: Mercado de Letras, 2001.

“Leite com manga, morre!": da hipotaxe adverbial no português em uso. 1993. Tese (Doutorado) - Pontifícia Universidade Católica de São Paulo, São Paulo, 1993.

DIAS, M.; RODRIGUES, V. Justaposição: processo sintático distinto da coordenação e da subordinação? In: RODRIGUES, Violeta Virginia (Org.). Articulação de orações: pesquisa e ensino. Rio de Janeiro: UFRJ, 2010. p. 11-29.

DIAS, Maria de Lourdes; Vaz Sppezapria. A articulação hipotática em construções proverbiais justapostas. 2009. fls. Dissertação (Mestrado) - Universidade Federal do Rio de Janeiro, Rio de Janeiro, 2009.

FERREIRA, Michelli Bastos. Cláusulas condicionais: uma abordagem funcional - dicursiva. 2007. fls. Dissertação (Mestrado) - Universidade Federal do Rio de Janeiro, Rio de Janeiro, 2007.

FORD, Cecilia E. Variation in the intonation and punctuation of different adverbial clause types in spoken and written English. In: Discourse and grammar, Santa Barbara Papers, California, v. 2. p. 73-96, 1992.

FOX, Anthony. Intonation, accent and rhythm: studies in discourse phonology. Berlim; New York: De Gruyter, 1984.

GARCIA, Othon Moacir. Comunicação em prosa moderna. 3. ed. Rio de Janeiro: FGV, 1975. HALLIDAY, Mark. Functional Grammar. New York: Oxford University Press, 1994.

KURY, Adriano Gama. Novas lições de Análise Sintática. Rio de Janeiro: Ática, 2002.

LUFT, Celso Pedro. Gramática resumida. Porto Alegre: Globo, 1978.

MANN, W. C., THOMPSON, S. A. Relational propositions in discourse. Discourse Processes, v. 9, p. 57-90, 1986. http://dx.doi.org/10.1080/01638538609544632

NEY, João Luiz. Guia de análise sintática. Rio de Janeiro: [s.n.], 1955.

OITICICA, J. Manual de análise léxica e sintática. 6. ed. Rio de Janeiro: Francisco Alves, 1942.
RODRIGUES, Violeta Virginia. Articulação de orações: pesquisa e ensino. Rio de Janeiro, UFRJ, 2010.

ROCHA LIMA, Carlos Henrique da. Gramática Normativa da Língua Portuguesa. Rio de Janeiro: José Olympio, 1972.

SAID ALI, M. Gramática secundária da língua portuguesa. São Paulo: Melhoramentos, 1969.

SANDMANN, Antônio. A linguagem da propaganda. São Paulo: Contexto, 2010.

SOARES, Magda Becker; CAMPOS, Edson Nascimento. Técnica de redação. Rio de Janeiro: Imperial Novo Milênio, 1978.

Recebido em 16/04/2015

Aceito em 11/06/2015. 